\title{
Inovasi Dalam Program Entrepreneur Anak Usia Dini
}

\author{
Farah Rizkita Putri \\ ${ }^{1}$ Universitas Islam Nabdlatul Ulama Jepara \\ e-mail: farah@unisnu.ac.id
}

\begin{abstract}
Innovation is indicated through the process of developing children's creative ideas through entrepreneurial learning programs. This article describes how the innovation process can be carried out by children with a series of entrepreneurial program planning. The method used in this article is a qualitative approach and uses case study research designs. Based on observations in the field, that innovation carried out by children is related to features, functions, perspective relations, procedures, cause and effect and responsibility. The development of these innovations is carried out in teacher and child planning and implemented through the entrepreneurial program learning cycle. The results of this study have implications that children express creative ideas related to innovations made on each theme of the entrepreneur program. The creative idea related to the theme of the place in this research is that children make design invitations for parents at the communicating stage.
\end{abstract}

\section{Keyword: Learning Innovation, Entrepreneurship Program}

\begin{abstract}
Abstrak
Inovasi terindikasi dilakukan melalui proses pengembangan ide-ide kreatif anak melalui program pembelajaran entrepreneur. Artikel ini memaparkan bagaimana proses inovasi yang dapat dilakukan oleh anak dengan serangkaian perencanaan program entrepreneur. Metode yang dilakukan pada artikel ini adalah dengan pendekatan kualitatif dan menggunakan desain penelitian studi kasus. Berdasarkan pengamatan di lapangan, bahwa inovasi yang dilakukan anak terkait dengan fitur, fungsi, hubungan perspektif, prosedur, sebab akibat dan tanggung jawab. Pengembangan inovasi tersebut dilakukan pada perencanaan guru dan anak dan diimplementasikan melalui siklus belajar program entrepreneur. Hasil studi ini berimplikasi bahwa anak mengemukakan ide-ide kreatif terkait inovasi yang dilakukan pada setiap tema program entrepreneur. Ide kreatif terkait tema tempat pada penelitian ini adalah anak membuat desain undangan untuk orangtua pada tahap communicating.
\end{abstract}

Kata Kunci: Inovasi Pembelajaran, Program Entrepreneur

\section{PENDAHULUAN}

Inovasi yang dilakukan pada proses pembelajaran menjadi hal penting. Selain karena inovasi dapat melatih kerangka berpikir anak, juga inovasi dapat membuat aktivitas pembelajaran menjadi menyenangkan. Setiap orang dapat menjadi seorang entrepreneur dengan mempelajari keterampilan yang dimiliki sehingga dapat menciptakan sebuah inovasi (Dees, 1998). Dalam ranah pendidikan ini enterpeneur merupakan inovasi baru dalam kurikulum sekolah di dunia (Brock and Kim, 2011; 
Pache and Chowdhury's, 2012). Sebuah studi menyebutkan bahwa inovasi dalam entrepreneur yang dimaksud adalah mengidentifikasi ide-ide yang dapat membuat tantangan dari aktivitas anak. Hal ini berarti inovasi yang dilakukan adalah serangkaian perencanaan, pengelolaan sehingga mendapatkan hasil akhir terlihat bagaimana inovasi berhasil (Kanter, 1986; Peters and Waterman, 1982; Pinchott, 1985; Seymour, 2007). Jika ingin melakukan inovasi maka ada tahap yang dilakukan agar ide-ide kreatif dapat terarah diantaranya anak melakukan observasi, anak mencari literature yang sesuai dengan konsep inovasi akan dilakukan (Morrison \& Johnston, 2003; Prahalad and Doz, 1981; Schmidt Soper \& Bernaciak, 2011). Selain itu program entrepreneur juga memiliki nilai-nilai inovasi yang tinggi terkait dengan membangun ide baru, potensi dalam kreativitas anak, berpikir kreatif dalam memecahkan suatu masalah, sebagai leader dalam kelompok sehingga dapat proaktif dan membangun komunikasi yang baik (Covin \& Slevin, 1988; Gupta, dkk, 2004; Huei, 2007; Stuart \& Abetti, 1987; Timmons, 1999). Program entrepreneur memberikan solusi bagi pembelajaran yang akan mengasah inovasi anak. Terkait ide, kreativitas, cara menyelesaikan masalah dan inovasi yang dilakukan dapat berpengaruh pada perilaku anak di masa yang akan datang. Misalnya berbagai macam keterampilan yang harus dimiliki anak, maupun prestasi yang diraih sebagai bentuk kebangaan orangtua. (Chaganti,dkk, 2002; McClleland, 1964)

\section{METODE}

Artikel ini menggunakan metode penelitian kualitatif dengan desain penelitian studi kasus. Subjek pada penelitian studi kasus adalah kelas B1 TK Santa Ursula Bandung. Sekolah ini dipilih sebagai lokasi penelitian karena sudah menerapkan program entrepreneur berbasis inovasi sejak tahun 2009. Inovasi yang dijadikan objek pada program entrepreneur adalah apa saja yang akan dilakukan untuk merencanakan inovasi yang akan dilaksanakan, bagaimana pelaksanakan dari inovasi tersebut, dan yang terakhir adalah evaluasi dari perencanaan dan pelaksanaan inovasi yang telah dilaksanakan. Teknik pengumpulan data menggunakan observasi dan wawancara. Observasi dilakukan pada tahapan program entrepreneur kemudian wawancara dilakukan kepada guru kelas dan kepala sekolah TK Santa Ursula.

\section{HASIL DAN PEMBAHASAN}

Inovasi pada program entrepreneur pada TK Santa Ursula terletak pada perencanaan program entrepreneur dalam komponen belief. Pada komponen ini sekolah merencanakan inovasi apa yang akan diunggulkan dalam tema. Perencanaan yang dilakukan untuk menentukan inovasi berdasarkan panduan focus innovation pada program entrepreneur. Fokus inovasi tersebut mencakup fitur (features) yaitu anak mempelajari tantang, unsur, warna, ukuran, model-model serta unsur-unsur yang memberikan nilai agar dapat menemukan pola dan model baru yang dapat diciptakan. Fungsi (function) yaitu anak mempelajari kegunaan atau peran dari benda atau elemen untuk dapat mencari alternatif baru yang lebih baik. Hubungan (connection) yaitu anak belajar tentang pola-pola hubungan dan pengaruh yang terjadi sehingga dapat belajar untuk membentuk pola, makna, alternatif hasil baru. Perspektif (perspective) yaitu anak belajar untuk melihat, mempelajari sesuatu dari beberapa segi (perspektif) sehingga data mengambil kesimpulan yang lebih komprehensif dan dapat menentukan hal yang paling bernilai. Prosedur (Procedure) yaitu anak belajar pola-pola prosedur atau langkahlangkah agar dapat menentukan langkah-langkah yang efisien dan efektif dalam menyelesaikan sebuah kegiatan atau kerja dan menciptakan nilai. Sebab akibat (causation) yaitu anak belajar tentang sebab akibat yang timbul karena perilaku manusia atau kejadian alam sehingga dapat mendorong terciptanya rasa tanggungjawab dan perilaku antisipatif. Tanggungjawab (responsibility) yaitu anak belajar tentang bentuk-bentuk tindakan atau kegiatan sebagai wujud dari pengetahuan, sikap dan skill dari proses belajar (Ciputra, 2009).

Berbagai inovasi di atas dilakukan serangkaian perencanaan oleh guru sebelum program entrepreneur dilaksanakan. Pada tema tempat fokus inovasi yang direncanakan melalui empat aspek 
inovasi, yaitu responsibility mencakup sikap apa yang perlu dimiliki untuk menghasilkan bentuk produk yang kreatif dan inovatif. Selain itu, aspek responsibility juga merencanakan inovasi mencakup apa akibat bila tidak memiliki tanggungjawab terhadap tugas yang dikerjakan. Aspek yang kedua yaitu procedure mencakup langkah-langkah apa saja digunakan untuk melestarikan budaya. Kemudian aspek yang ketiga adalah procedure kerja mencakup bentuk kegiatan yang mencerminkan pemahaman dan tanggungjawab anak dalam menciptakan performance yang kreatif, inovatif serta mampu menumbuhkan rasa peduli dan cinta tanah air. Aspek yang keempat yaitu performance mencakup yang kreatif inovatif dan dapat menumbuhkan rasa peduli dan cinta terhadap tanah air serta mampu menimbulkan apresiasi dari orang lain. Berdasarkan Fokus inovasi yang telah disusun maka perencanaan selanjutnya adalah menentukan judul tema besar untuk tahap communicating.

Fokus inovasi juga bisa direncanakan pada tahap planning. Tahap ini anak merencanakan kegiatan melalui ide-ide yang akan ditampilkan saat tahap communicating nanti. Pada tahap ini guru dan anak dapat berinovasi mengenai kreasi apa yang akan diciptakan yang tentunya berkaitan dengan tema yang sedang dilaksanakan (Ciputra, 2009). Selain itu, entrepreneur dapat menunjang aktivitas anak ke dalam hal yang dapat menstimulasi ide-ide kreatif anak dalam berinovasi sehingga anak dapat tumbuh aktif dan kecenderungan anak mengambil risiko dari kegiatan yang menantang dan kontrol diri untuk memecahkan masalah. (Covin and Slevin, 1991; Miller, 1983); Kirzner, 1973; Stevenson and Jarillo, 1990). Sebuah studi menyebutkan bahwa inovasi dalam entrepreneur yang dimaksud adalah mengidentifikasi ide-ide yang dapat membuat tantangan dari aktivitas anak. Hal ini berarti inovasi yang dilakukan adalah serangkaian perencanaan, pengelolaan sehingga mendapatkan hasil akhir terlihat bagaimana inovasi berhasil (Kanter, 1985; Peters and Waterman, 1982; Pinchott, 1985; Seymour, 2007). Jika ingin melakukan inovasi maka ada tahap yang dilakukan agar ide-ide kreatif dapat terarah diantaranya anak melakukan observasi, anak mencari literature yang sesuai dengan konsep inovasi akan dilakukan (Morrison \& Johnston, 2003; Prahalad and Doz, 1981; Schmidt Soper \& Bernaciak, 2011). Tema tempat semester genap ini, guru merencanakan akan membuat drama musikal dengan judul "I love Indonesia", inovasi yang dilakukan adalah membuat undangan untuk orangtua, seperti kutipan di bawah ini:

"Miss merry bertanya pada anak-anak kalo describe undangan ada apa aja ya kemudian anak-anak secara bergantian menjawab: nama, kertas, pita, tulisan, love, ada foto orangnya. Kemudian miss merry menjelaskan undangan seperti apa yang harus dibuat adalah yang bertema Indonesia sebagai tema tempat. Indonesia terkenal apanya ya tanya miss merry? ada yang menjawab jojo menjawab rumah adat, brian menjawab monas Jakarta, aaron menjawab alat musik tradisionalnya, juan menjawab budayanya. Kemudian miss merry menjelaskan babwa anak-anak bisa mendesain rumah adat, atau alat musik, atau pakaian adat, atau tarian tradisional di kertas hvs yang dibagikan, jadi nanti undangan akan diseleksi misalnya jojo bagus rumah adatnya akan di edit, carol bagus gambar tariannya akan di edit, enzo bagus gambar alat musiknya akan di edit dan dijadikan satu dalam desain undangan. Kemudian anak-anak yang sudah memiliki ide untuk membuat desain mengambil kertas hvs secara bergantian lalu mengambil pensil dan duduk di kursinya masing-masing. Ada beberapa anak yang belum memiliki ide kemudian miss merry mengulas kembali kegiatan eksploring pada saat menonton video, pada saat ke TMII dan anakanak boleh bebas menggambar desain undangan sesuai dengan ingatan tentang eksploring lalu. Kegiatan ini terpotong dengan ekstra balet, maka anak perempuan yang ikut ballet. Anak-anak lain jika sudah selesai menggambar ditebalkan menggunakan spidol warna hitam, kemudian di warnai menggunakan pensil warna. Kegiatan membuat desain undangan ini diselesaikan pada hari ini karena akan di edit dan di seleksi oleh guru untuk persiapan communicating. "(Observasi, Mei 2018)

Berdasarkan data observasi di atas inovasi dapat berkembang jika konsep materi tentang tema tempat sudah dapat dipahami oleh anak. Pemahaman konsep materi ini penting untuk dilakukan pertama kali agar fokus inovasi yang sudah direncanakan pada komponen belief pada program entrepreneur terlaksana dengan lancar dan terarah. Pada tahun 2008 di Eropa program entrepreneur menjadi suatu inovasi dalam sistem pendidikan. Hal ini terbukti dari beberapa penelitian sebelumnya bawa program enterpreneur ini dapat berlanjut hingga jenjang selanjutnya, multidimensi, kemudian banyak inovasi yang dapat mengembangkan diri anak. (Fayolle, 2003). Setiap orang dapat 
menjadi seorang entrepreneur dengan mempelajari keterampilan yang dimiliki sehingga dapat menciptakan sebuah inovasi (Dees et al., 2001). Dalam ranah pendidikan ini enterpeneur merupakan inovasi baru dalam kurikulum sekolah di dunia (Brock and Kim, 2011; Pache and Chowdhury's, 2012).

Literatur terdekat yang dapat dijadikan rujukan sebagai penunjang inovasi anak adalah berasal dari orangtua. Hal ini dibuktikan dalam sebuah studi bahwa peran orangtua dapat membantu anak dalam membantu anak dalam membangun konsep atau ide kreatif untuk berinovasi (Birkinshaw, 1997). Pada tahap eksploring ketika anak diberi tugas untuk membawa materi konsep tema yang sedang dilaksanakan, pada tahap ini anak dapat berkolaborasi dengan orang tua untuk membangun konsep terkait ide-ide kreatif dalam pengembangan inovasi tema tersebut. Sehingga ide-ide kreatif terkait inovasi yang akan dilakukan dapat dipenagruhi oleh lingkungan sekitar anak, tetapi tidak keluar dari perencanaan pada komponen belief pada program entrepreneur.

\section{KESIMPULAN}

Program entrepreneur terkait dengan inovasi yang dilakukan adalah di dalam entrepreneur terdapat ide-ide kreatif yang begitu sangat berpengaruh dalam perkembangan inovasi maupun membangun kreativitas baru. Hal ini menjadi penting untuk anak usia dini terutama karena dapat menjadi salah satu stimulus dalam menjalankan tugas perkembangan anak. Sehingga anak dapat menciptakan inovasi melalui ide-idenya tanpa sadar dengan inovasi tersebut anak dapat berkreasi, mencoba hal baru, memecahkan masalah dan anak dapat mencapai tujuan dari suatu projek, seperti tema tempat kali ini anak dapat membuat inovasi desain undangan pada orangtua. Hal tersebut tidak perlu dilakukan oleh sekolah tetapi dalam program entrepreneur ini melibatkan anak dalam pengembangan tema tersebut. Konsep dalam program entrepreneur dalam pengembangan inovasi ini melalui serangkaian perencanaan dan diaplikasikan melalui siklus belajarnya. Siklus tersebut sebagai jalan dimana inovasi dapat berkembang yang terutama anak dapat memahami konsep dari setiap tema terlebih dahulu yang sedang dilaksanakan.

\section{REFERENSI}

Brock, D. D. \& Kim, M. (2011). Social entrepreneurship education resource handbook. Ashoka U, the University Division of Ashoka: Innovators for the Public

Covin, J.G. and Slevin, D.P. (1988) The Influence of Organization Structure on the Utility of an Entrepreneurial Top Management Style. Journal of Management Studies, vol.25, 217-59.

Chaganti, R. \& Greene, P.G. 2002. "Who Are Ethnic Entrepreneurs? A Study of Entrepreneurs' Ethnic Involvement and Business Characteristics." Journal of Small BusinessManagement vol. 40(2): 126-143

Dees, G. (1998). The meaning of social entrepreneurship. Kauffman center for entrepreneurial leadership, Ewing Marion Kauffman FoundationW orking Paper

Gupta, V., MacMillan, I.C. and Surie, G. (2004) Entrepreneurial Leadership: Developing and Measuring a Cross-Cultural Construct. Journal of Business Venturing, vol.19, 241-60.

Huei, M.C. (2007). Entrepreneurial Leadership and New ventures: Creativity in entrepreneurial temas. Journal creativity and innovation management Vol. 16 No3 2007 doi:10.1111/j.1467-8691.2007.00439.x

Kanter, R. M. (1986). 'Supporting innovation and ven- ture development in established companies', Journal of Business Venturing, vol.1(1), pp. 47-60

McClelland,D. "Business drive and National Achievment dalam Amitai, E \& Eva, E (1964). Social change. New york: Basic Book 
Morrison,A. Johnston, B. (2003). Personal Creativity for Entrepreneurship. Active Learning in Higher Education. Vol. 4 (2), 145-158

Pache, A. C. \& Chowdhury, I. (2012). Social entrepreneurs as institutionally embedded entrepreneurs: Toward a new model of socialentrepreneurship education. Academy of Management Learning \& Education. vol.11 (3): pp. 494 - 510.

Peters, T. J. and R. H. Waterman (1982). In Search of Excellence. Harper \& Row, New York.

Pinchott, G. III (1985). Intrapreneuring. Harper \& Row, New York.

Prahalad, C. K. and Y. L. Doz (Summer 1981). 'An approach to Strategic Control in MNCs', Sloan Man- agement Review, pp. 5-13

Seymour, N. A. (2007). Defining Entreprenurial Activity: Definitions supporting frameworks for data collection. Sydney: OECD

Schmidt, J. Soper, J. and Bernaciak, J. (2011) Assessing creativity in the entrepreneurship classroom. Presented at Small Business Institute Conference, Bonita Springs, Florida.

Stuart, R. and Abetti, P.A. (1987) Start-Up Ventures: Toward the Prediction of Initial Success. Journal of Business Venturing, vol. 2, 215-30.

Timmons, J.A. (1999) New Venture Creation: Entrepreneurship in the 1990s, 3rd edn. Irwin, Homewood, IL. 